\title{
Evolutionary Psychology: The Burdens of Proof
}

\author{
ELISABETH A. LLOYD* \\ History and Philosophy of Science Department \\ Biology Department \\ Indiana University \\ Goodbody Hall 130 \\ Bloomington, IN 47405 \\ U.S.A. \\ E-mail: ealloyd@indiana.edu
}

\begin{abstract}
I discuss two types of evidential problems with the most widely touted experiments in evolutionary psychology, those performed by Leda Cosmides and interpreted by Cosmides and John Tooby. First, and despite Cosmides and Tooby's claims to the contrary, these experiments don't fulfil the standards of evidence of evolutionary biology. Second Cosmides and Tooby claim to have performed a crucial experiment, and to have eliminated rival approaches. Though they claim that their results are consistent with their theory but contradictory to the leading non-evolutionary alternative, Pragmatic Reasoning Schemas theory, I argue that this claim is unsupported. In addition, some of Cosmides and Tooby's interpretations arise from misguided and simplistic understandings of evolutionary biology. While I endorse the incorporation of evolutionary approaches into psychology, I reject the claims of Cosmides and Tooby that a modular approach is the only one supported by evolutionary biology. Lewontin's critical examinations of the applications of adaptationist thinking provide a background of evidentiary standards against which to view the currently fashionable claims of evolutionary psychology.
\end{abstract}

Key words: adaptation, evolutionary psychology, reasoning

\section{Introduction}

Richard C. Lewontin's interventions against the acceptance of speculative, untested, yet socially-influential claims about human evolution - the most politically significant parts of "sociobiology" - stand as one the most important and controversial aspects of his career. The criticisms expressed in his papers on adaptation, ${ }^{1}$ and in the famous paper he co-authored with Stephen Jay Gould, ${ }^{2}$ have spurred methodological self-awareness about claiming adaptation in many quarters. While Lewontin's papers have attained the status of obligatory citations, this does not mean that their critical conclusions have been fully absorbed. Indeed, there are recent authors who present 
G. C. Williams' 1966 book - which was, after all, about the high standards that must be enforced in order to claim an evolutionary adaptation - and Gould and Lewontin's 1979 paper - which embodied an insistence on the high standards that must be enforced in order to claim an evolutionary adaptation - as being on opposite sides of the fence with regard to evolutionary adaptation. $^{3}$

Chief among those who claim to live in a post-Lewontinian age of adaptationism - one where an enlightened and modest approach to adaptation is practiced, and the strict standards of scientific evidence enthusiastically adhered to - are those practicing what they call "evolutionary psychology," most prominently, Leda Cosmides and John Tooby. ${ }^{4}$ Among the most widely touted experimental evidence for this newly-dubbed field of inquiry is Leda Cosmides' dissertation research on a laboratory reasoning task. ${ }^{5}$ From this evidence, she claims to show 'how evolutionary biology can contribute to the study of human information-processing mechanisms" (1989: p. 263). These experiments are claimed to provide strong support for her evolutionbased "Social Contract theory," and to contradict the most promising nonevolutionary theory of her opponents - the "Pragmatic Reasoning Schemas" of Cheng and Holyoak. Thus, evolutionary theory is used to help design experiments "to discover previously unknown psychological mechanisms" (Cosmides, Tooby and Barkow 1992: p. 10). Moreover, Tooby and Cosmides have claimed complete empirical victory:

Our evolutionarily derived computational theory of social exchange allowed us to construct experiments capable of detecting, isolating and mapping out previously unknown cognitive procedures. It led us to predict a large number of design features in advance - features that no one was looking for and that most of our colleagues thought were outlandish (Cosmides and Tooby 1989). Experimental tests have confirmed the presence of all the predicted design features that have been tested for so far (1995: p. 91).

These claims did not go unnoticed. The paper in which Cosmides' experimental results were reported won the AAAS Behavioral Science Research Prize, and was selected by the judges "because of its substantial and surprising increase in understanding of the rules of thought." $"$ The collection of essays co-edited by Cosmides, Tooby, and Jerome Barkow, the Adapted Mind, was reviewed very positively in many quarters. For example:

A subtle change of emphasis has been immensely productive. Facts are falling into place all over the field, with implications that stretch far beyond psychology (Economist). ${ }^{7}$ 
Cosmides and Tooby show that humans have evolved selective mechanisms for detecting violations of conditional rules when these rules mean cheating on a social contract (American Anthropologist). ${ }^{8}$

Cosmides and Tooby (1987) outlined a theoretically sophisticated and empirically productive method of analyzing human mental capacities as complex biological adaptations, sculpted over evolutionary time through natural and sexual selection (Adaptive Behavior). ${ }^{9}$

I shall discuss several problems with this research. First, the connections of Cosmides' "Social Contract Theory" to evolutionary biology - contrary to the claims of its promoters - are quite problematic. In addition, it seems that the ostensible links to evolutionary biology - rather than the experimental evidence - are doing much of the work of eliminating rival psychological hypotheses. Once the exaggerated and ill-reasoned claims are removed, the experiments appear to support a non-evolutionary psychological theory at least as strongly: in fact, none of the usual burdensome evidential requirements for an evolutionary hypothesis are even attempted. Evolutionary psychologists are primarily using evolutionary theory to attempt to eliminate other competing theories within psychology, without regard to - and, in fact, in violation of - the standards of evolutionary biology. In what follows, I shall describe briefly the Cosmides theory and its evidence and problems, review updated evidence within psychology, and finally, discuss the relation of evolutionary psychology to evolutionary biology. Part I of this paper will focus on the two leading psychological theories; in Part II, I consider the evolutionary aspects of Social Contract theory.

I should clarify immediately - I am not at all opposed to the application of evolutionary biology to human and animal reasoning, or to psychology more generally. Cosmides' theory and experiments are, in many ways, heading in an exciting direction; to the extent that cognitive psychology has focused on the rules of logic as the ideal form of reasoning, other, more pragmatic, social, or biological bases for reasoning have been neglected. In addition, the general move towards reuniting psychological research and explanation with evolutionary biology is undoubtedly a positive step. My criticisms in this paper reflect concerns that the claims on behalf of the evidence have been overstated, and that evolutionary standards of evidence have been neglected. It is because I think that evolutionary approaches are among the most scientifically promising and robust, that I am concerned about the widespread and lessthan-critical acceptance of this body of work. It is one of the most pernicious aspects of the present climate of discussion, that the situation is often set up as a forced choice between accepting the particular theories and oversimplified principles of evolutionary psychology, or retreating to a pre-Darwinian denial of the fact that we are evolved animals. 


\section{Part I. Two psychological theories}

\section{Cosmides, the Wason selection task, and its peculiar "content effects"}

Cosmides' experiments were laboratory tests of the subjects' aptitude at a certain kind of logical problem. This Wason selection task is a test of the application of conditional logical reasoning. Experiment subjects are given a conditional rule, with the form, if $p$ then $q$, and are then asked to select which of four given cards must be turned over to decide whether or not the rule holds. Each card has information regarding whether $\mathrm{p}$ holds on one side, and whether q holds on the other. So, the subject is presented with four cards facing up: p; $\sim \mathrm{p} ; \mathrm{q} ; \sim \mathrm{q}$, each of which says on the back whether the other variable holds or not.

The correct response according to standard formal logic is to examine the $\mathrm{p}$ and the $\sim \mathrm{q}$ cases (as these are the only ones that could make the conditional false). When the test is put purely in terms of p's and q's, subjects perform poorly, usually neglecting to turn over the $\sim$ q card. If, however the rule is, "If you are to drink alcohol, then you must be over eighteen", subjects are significantly more successful in producing the logically correct answer (Cheng and Holyoak 1989: p. 286). Because this difference seems to depend on the content of the rule and not on its form, the resulting difference in performance is called a "content effect." Cognitive psychologists are thus faced with the challenge of explaining why there are content effects, i.e., how non-formal aspects of reasoning produce difference in performance on these tasks.

Research into these content effects has been pursued since the late 1960's, and several theories have been proposed to explain them. Cosmides presented her social contract (SC) theory as superior to the two leading alternatives: availability-type theories; and the "Pragmatic Reasoning Schemas' (PRS) theory proposed by Patricia Cheng and Keith Holyoak. In fact, she claims that her experiments have the structure of crucial experiments - that is, they don't simply provide positive support for her social contact theory, they simultaneously provide evidence against the availability and pragmatic reasoning theories.

One of the points of contention about content effects is whether they result from what psychologists call 'domain-specific' or 'domain-general' cognitive mechanisms. Briefly, domain-general mechanisms are understood as broad mental capacities, which may be used to solve a wide range of cognitive problems, whereas domain-specific mechanisms are much more limited in their ability. Tooby and Cosmides characterize the contrast as follows:

Does the mind consist of a few, general-purpose mechanisms, like operant conditioning, social learning, and trial-and-error induction, or does it also include a large number of specialized mechanisms, such as a language 
acquisition device ... mate preference mechanisms ... sexual jealousy mechanisms, mother-infant emotion communication signals ... social contract algorithms, and so on? (1992: p. 39) ${ }^{10}$

Availability theories of the content effect assume a completely general reasoning schema, and they predict that performance on the selection task will depend on familiarity or past experience with the situation. I think it's fair to say that much of the experimental data disconfirms this type of theory; while availability theories claim that performance rests on specific experience, such experience was not found to produce a content effect (Cheng and Holyoak 1985). This leaves us with the two content-specific reasoning theories, Cosmides' Social Contract theory, and Cheng and Holyoak's Pragmatic Reasoning Schemas theory.

On Cosmides and Tooby's account, the ability to perform reasoning about social contracts is evolutionary in origin. According to Cosmides, "a social contract relates perceived benefits to perceived costs, expressing an exchange in which an individual is required to pay a cost (or meet a requirement) to an individual (or group) in order to be eligible to receive a benefit from that individual (or group)" (1989: p. 197). As Gigerenzer and Hug describe the evolutionary rationale:

For hunter-gathers, social contracts, that is, cooperation between two or more people for mutual benefit, were necessary for survival. But cooperation (reciprocal altruism) cannot evolve in the first place unless one can detect cheaters (Trivers 1971). Consequently, a set of reasoning procedures that allow one to detect cheaters efficiently - a cheat-detector algorithm - would have been selected for. Such a 'Darwinian algorithm' would draw attention to any person who has accepted the benefit (did he pay the cost?) and to any person who has not paid the cost (did he accept the benefit?). Because these reasoning procedures, which were adaptations to the hunger-gatherer mode of life, are still with us, they should affect present-day reasoning performance (Gigerenzer and Hug 1992: p. 130).

Pragmatic reasoning schemas provide a third approach to explaining content effects. According to this theory, pragmatic reasoning schemas - patterns of reasoning - are induced through experience within goal-defined domains. ${ }^{11}$ While the schemas themselves are content-dependent, they are created by inductive cognitive processes that are content-independent. The developers of the theory, Patricia Cheng and Keith Holyoak, proposed that

People often reason using neither syntactic, context-free rules of inference, nor memory of specific experiences. Rather, they reason using abstract knowledge structures induced from ordinary life experiences, 
such as 'permissions', 'obligations', and 'causations'. Such knowledge structures are termed pragmatic reasoning schemas. A pragmatic reasoning schema consists of a set of generalized, context-sensitive rules which, unlike purely syntactic rules, are defined in terms of classes of goals (such as taking desirable actions or making predictions about possible future events) and relationships to these goals (such as cause and effect or precondition and allowable action) (Cheng and Holyoak 1985: p. 395).

Cheng and Holyoak investigated a range of content effects in the Wason selection task; their analysis focuses on actions to be taken and conditions to be satisfied:

If you take action $\mathrm{A}$, then you must first satisfy precondition $\mathrm{P}$

To be permitted to do A, you must first do $\mathrm{P}$

Variants of these rules constitute "permission" and "obligation" schemas, according to PRS theory; these are general schemas set up by experience which guide inferences within specific goal-defined domains. For example, the rule, "If you are to drink alcohol, then you must be over eighteen," is a conditional permission rule. Note that this rule can be mapped onto the material conditional, if $\mathrm{p}$ then $\mathrm{q}$. Nisbett and Cheng (1988) discussed combination obligation/permission rules that do not map onto the material conditional, and predicted that performance would follow the pragmatic rule rather than obeying the laws of formal logic.

It was within this tradition of Wason selection task experiments that Cosmides conducted her experiments. She then claimed that her theory was sharply different from Cheng and Holyoak's.

\section{2. "Crucial experiments" and the elimination of PRS}

Cosmides and Tooby have repeatedly attempted to frame the Cosmides experiments as "crucial experiments"; a crucial experiment is one that will, once the results are in, favor decisively one hypothesis over the other alternatives. The goal, with an experimental set-up involving a crucial experiment, is to eliminate one hypothesis completely. The experimental results presented in Cosmides' paper should not be understood as the results of crucial experiments. In fact, the experiments do not resolve the competition between Cosmides' Social Contract theory and Cheng and Holyoak's Pragmatic Reasoning Schemas.

While the experiments comparing availability theory and Cosmides' Social Contract theory can reasonably be interpreted to favor the latter, those designed to compare Pragmatic Reasoning Schemas and Social Contract theory simply do not favor Cosmides' view, contrary to her claims. Rather, 
evolutionary theory is brought in to tip the balance in favor of Social Contract theory. Given that evolutionary theory thus plays the central role in eliminating competing hypotheses, according to Cosmides' own argument, it is highly significant that her presentations of evolutionary theory are seriously flawed. We will focus briefly on the points at which Cosmides' argument rests on evolutionary theory, emphasizing the centrality of evolutionary theory to her refutation of the clearest and most plausible competing hypothesis.

Cosmides claims that Pragmatic Reasoning Schemas theory has "many theoretical and empirical problems" (Cosmides 1989: p. 193). She begins her attack by reinterpreting their experiments, in which they got a content effect, as social contract problems in disguise. Cheng and Holyoak explicitly gave a social purpose to their tasks, but Cosmides claims that they did more than this - they also gave contextual information, which included a cost-benefit structure. In these cases, then, the permission schemas described by Cheng and Holyoak and Cosmides' Social Contract theory give the same predictions. But Cosmides emphasizes two points of difference between the two theories: the structure of the proposed algorithms, and their origin.

\section{Structure of proposed algorithm}

In contrast to the problems with testing the competing hypotheses about the origin of the schemas, discussed below, the differences in the structures of the proposed algorithms are supposed to be directly testable. These testable differences are described as differences in the "proposed level of representation and domain of operation" (Cosmides 1989: p. 235). In other words, Cosmides claims that her 'cost-benefit' analysis involves a different level of abstraction than Cheng and Holyoak's permission/obligation schemas. In Social Contract theory, the benefits and costs are understood in terms of the utilities for the actors. (In evolutionary terms, the utilities must be understood in terms of fitness parameters.)

In PRS theory, in contrast, there are actions to be taken and conditions to be satisfied. But what is the real difference between costs and actions to be taken? Cosmides modifies the meaning of 'social exchange' to include cases in which the 'cost' is simply 'meeting a requirement'; such an expansion of the idea of 'cost' violates the notion of exchange, argue Cheng and Holyoak, since a requirement "is not generally an exchangeable entity that can be given in payment" to some individual or group, for the receipt for a benefit (Cheng and Holyoak 1989: p. 288). If we acknowledge that "meeting a requirement" is meaningfully similar to "fulfilling a precondition," then the remaining difference between the two theories is that permission/obligation schemas focus on an 'action taken,' while social contract theory requires that there be a 'benefit'. 
Cosmides argues that a permission rule is a social contact rule only when the 'action taken' is a 'benefit' and the 'precondition' is a 'cost'. But why call this a different "level of representation"? The issue is simply that the permission rules, according to her analysis, have a larger domain than the social contact rules. Nevertheless, Cosmides proposes critical tests "to decide which kind of representation is psychologically real: the action-precondition representation, or the benefit-cost representation" (1989: p. 237). But this is too strong; these are not the only two choices. It is quite plausible that neither hypothesis under consideration represents something "psychologically real'. Later, her conclusions are even stronger. She writes, "cost-benefit representations of Social Contract theory have psychological reality," and she claims to have established that "Social Contract theory posited the correct domain of operation" (1989: p. 253). It is central to her claim that only those permission rules having the cost-benefit structure of a social contract actually work (1989: p. 254).

Cosmides' strategy seems to be to reinterpret every case in which Cheng and Holyoak found a robust content effect, as actually a social contractin-disguise. Cosmides even claims that a content-free permission rule is similarly a social contract.

Cheng and Holyoak's rule is:

If you take action $\mathrm{A}$, then you must first satisfy precondition $\mathrm{P}$

To be permitted to do A, you must first do $\mathrm{P}$

Cosmides argues that while this rule does not mention costs and benefits, it still "has an implicit cost-benefit structure." This is because saying that one must satisfy a precondition "is just another way of saying that one must pay a cost or meet a requirement" (1989: p. 239).

But "paying a cost" and "meeting a requirement" or precondition are simply not the same thing. The precondition may be something completely innocuous, with no element of perceived cost to it, or even with an element of pleasure.

Consider the following example: You are permitted to donate blood, if you are HIV-negative. Is the condition of being HIV-negative a cost? No, it is a precondition. This is a genuine permission rule, and not a social contract. There is no sensible way that we would want to interpret this as a cost-benefit relation. Note that it is important to the original logic motivating the "cheatdetector algorithm" that the cost actually be a cost; otherwise, there would be no motivation at all to look for cheaters.

\section{Origins of proposed algorithms}

For the sake of argument, let us grant that Cosmides' experiments do produce results in which the participants seem to be using a 'cost'-benefit structure in 
their reasoning. Even so, this result does not eliminate the primary competing hypothesis, Pragmatic Reasoning Schemas theory, which can be expanded to account for these data. (Just as the original Social Contract theory definition of 'cost' was modified to include 'requirement'.) But Cosmides claims that there is a much more basic difference between the two theories. Cosmides ultimately appeals to the greater a priori plausibility of Social Contract theory, which is supposedly based on evolutionary theory, to eliminate the competing hypothesis. A crucial part of her argument is that the pragmatic reasoning schemas cannot explain the origin of the reasoning mechanism that is used.

Under Pragmatic Reasoning Schemas theory, the schemas come from some form of induction. The rules of inference are a product of experience, which is structured by innate information-processing mechanisms that are domain-general. Under Social Contract theory, in contrast, the rules of inference "are themselves innate, or else the product of 'experience' structured by innate algorithms that are domain-specific" (Cosmides 1989: p. 235).

Cosmides asserts that Cheng and Holyoak's claim regarding the origin of schemas is unfalsifiable (1989: p. 235). This is clearly wrong. One could determine experimentally what sorts of experience are relevant for a particular schema, then look for cross-cultural variation in that sort of experience, and finally, determine whether that variation correlates with variation in schema present cross-culturally. One could then test whether inference rules are different.

Furthermore, Cosmides admits that, in her case, the origins claim is not directly testable, but argues that the claim is "subject to plausibility arguments based on existing data". Cosmides claims explicitly that alternative explanations fail because their basic assumption of domain-general mechanisms is false, and she claims that this falsity is demonstrated by evolutionary theory. Natural selection, she claims, would have produced special purpose, domain-specific mental algorithms (Cosmides 1989: p. 193).

The basic structure of her argument is:

1) There are domain-specific processes;

2) These processes are based in evolution;

Therefore,

3) They are genetically based.

Hence, she is making a claim about the origin of specialized processes, although she admits she's not testing this claim. The evidence she offers for this evolutionary conclusion, in the context of these specific experiments, is: first, that reasoning performance is found to depend on content; and second, that the alteration in performance occurs in the "predicted adaptive direction." 
She must, therefore, establish indirectly that this specificity is genetic, as opposed to being the result of the particular environment or experience; otherwise, there is no real difference between her hypothesis and that of Cheng and Holyoak. ${ }^{12}$

Part II of her paper is meant to address this very question. She must show that the evidence that she has for the existence of specific processes is not a result of experience interacting with a more general social-learning mechanism. Evolutionary theory is used to predict the existence of specific processes. On my analysis of her argument, then, the gap between her conclusion and the empirical evidence she offers is filled in by the putative power of evolutionary prediction.

The concrete evolutionary claims that are called upon to do this job of eliminating the leading alternative hypothesis include a conclusion stated at the beginning of the paper. Primary among the evolutionary assumptions is modularity; in defense of this extremely strong physiological or functional assumption, she cites Noam Chomsky - a linguist known for his hostility to Darwinian explanations - and Jerry Fodor - a philosopher whose speculative book, The Modularity of Mind, was deeply embedded in a particular research program in cognitive science, and was notably uninformed by evolutionary thought (Cosmides 1989: pp. 190, 193; cf. Cosmides and Tooby 1992: p. 165). But the main reason for expecting to find extremely specialized modules is evolutionary, according to Cosmides:

The more important the adaptive problem, the more intensely selection should have specialized and improved the performance of the mechanism for solving it (Darwin 1859/1958; Williams 1966). Thus, the realization that the human mind evolved to accomplish adaptive ends indicates that natural selection would have produced special-purpose, domain-specific, mental algorithms - including rules of inference - for solving important and recurrent adaptive problems (such as learning a language; Chomsky 1975, 1980) (Cosmides 1989: p. 193).

She says that it's clear that while some mechanisms in the cognitive architecture "are surely domain-general, these could not have produced fit behavior under Pleistocene era conditions (and therefore could not have been selected for) unless they were embedded in a constellation of specialized, contentdependent mechanisms" (1989: p. 194). One might ask why they could not have produced fit behavior; this claim seems to assume the impossibility of general mechanisms leading to adaptive behavior. In support of this assumption, Cosmides cites a number of papers in which it is assumed that the problems solved by the cognitive mechanisms in question are: 1) fixed; 2) under strong selection pressure; and 3) have only one solution (1989: p. 195; cf. Cosmides 1985; Cosmides and Tooby 1987; Symons 1987; and Tooby 
1985). I need not belabor the fact that none of these assumptions are given empirical support in these papers.

In summary, Cosmides uses the claim that evolutionary theory allows for or predicts her favored type of mechanism to discard or eliminate obvious competing hypotheses. Given the invalidity of her evolutionary assumptions, to be discussed in a moment, the fact that they play a central role in her arguments brings her conclusions into doubt. This does not affect, of course, the fact that there are content effects of a certain, interesting type in her experimental results, but it does bring her conclusions about these results into question.

\section{Updates and revisions}

Cosmides' initial presentation of her theory and experiments raised a great many questions. Among the most pressing was: what is the real difference between her Social Contract cases, and the permission and obligation schemas proposed by Cheng and Holyoak? Gerd Gigerenzer and Klaus Hug performed an elegant and powerful series of Wason selection task experiments to address this very problem (1992). As Gigerenzer and Hug's experiments showed, the social contract cases comprise one category of Cheng and Holyoak's pragmatic reasoning schemas.

Cosmides claimed that there was a sharp distinction between a Social Contract rule and a non-Social Contract permission rule. She also claimed that evolutionary theory predicted that people would be good at the logic task when there was a SC rule, but not if the rule was a non-SC rule. Gigerenzer and Hug rejected Cosmides' claim that if a rule is perceived as a social contract, then it will produce a content effect. They distinguished experimentally between cases of social contracts - which are, indeed, versions of permission or obligation schemas - and those in which the person is "cued into the perspective of a party who can be cheated" (1992: p. 127). Their experiments provided evidence that people are especially good at detecting cheaters to rules, and that their own role or perspective in the rule affected their performance.

Gigerenzer and Hug showed experimentally that the crucial factor producing a content effect is not whether a rule is a social contract rule; what mattered was whether a subject was cued into the perspective of one participating party in a requirement-benefit exchange, and whether the other party had the option of cheating (1992: p. 165). In other words, the fact that a rule is perceived as a social contract is insufficient for producing a content effect, contrary to Cosmides' claim. Moreover, there seem to be only terminological differences between Cosmides' "requirement-benefit" social contracts, and 
Cheng and Holyoak's permission/obligation schemas. Gigerenzer and Hug summarize:

It is the pragmatics of who reason from what perspective to what end (e.g., cheating detection) that seems to be sufficient [to account for the content effects]. Although Cosmides' prediction is at odds with this result, and although the distinctions between perspectives, and between social contract rules and Darwinian algorithms were not part of Cosmides' experiments, they nonetheless underlie SC theory (1992: p. 166).

I find this summary difficult to reconcile with Cosmides and Tooby's later claim that "experimental tests have confirmed the presence of all the predicted design features that have been tested so far" (1995: p. 91; emphasis added). The chart provided to back up this sweeping claim curiously omits Cosmides' initial predictions tying content effects to instances of social contracts (1995: p. 90).

Thus, Gigerenzer and Hug credit Cosmides for introducing the notions of the "cheating option" and "the cheater-detection algorithm" into research on this reasoning task, and they note that the notion of cheating itself implies that at least two parties with two different perspectives exist. Given Gigerenzer and Hug's experimental results showing the importance of these distinctions, I think it's fair to say that the Social Contract theory has advanced understanding of experimental conditional reasoning. Nevertheless, nothing in either Cosmides' original data or in Gigerenzer and Hug's data even addresses the underlying evolutionary claims. In fact, Gigerenzer and Hug note that the notion of "cheater-detection algorithm" "could also be derived from points of view other than an evolutionary one, such as from the work on children's understanding of deception as a function of their ability for perspective change (e.g., Wimmer and Perner 1983)" (Gigerenzer and Hug 1992: p. 130).

The most worrisome arguments offered by Cosmides, from my point of view, involved convoluted discussions of why evolutionary theory favored social contracts and disfavored permission and obligation schemas. While these have since been abandoned in their original form - since Gigerenzer and Hug's results more persuasively favored part of Cosmides' original hypothesis - specious evolutionary reasoning still appears in Cosmides and Tooby's attempts to eliminate rival approaches.

So, the good news is that a pattern of socially defined costs and benefits seems to enable or facilitate reasoning about social situations. Why this should be a surprise is not completely clear; the answer seems to lie in cognitive psychology's prior commitment to holding deductive formal logic as the natural form of human reasoning. Anyone who has taught formal 
logic knows that the material conditional violates intelligent and rational individuals' sense of fair reasoning.

The bad news is that these results have been tied to a dogmatic and oversold scientific program. While Gigerenzer and Hug make very clear, both at the beginning and end of their paper, that other, non-evolutionary explanations of the 'cheater-detection mechanism' are plausible (and, I would add, are not even addressed by any of the evidence), Cosmides, Tooby, and other promoters of evolutionary psychology claim that the evidence favors their and only their - evolutionary account.

\section{Uses of evolutionary biology}

Cosmides and Tooby advocate that cognitive science be guided by:

(1) Theories of adaptive function,

(2) Detailed analyses of the tasks each mechanism was designed by evolution to solve,

and

(3) The recognition that these tasks are usually solved by cognitive machinery that is highly functionally specialized (1995: p. 70).

Evolutionary biology seems so simple, elegant, and powerful; once the power of a selection process to produce evolutionary change is appreciated, it is tempting to apply this process to every situation. But, as evolutionary theorists since Darwin have recognized, evolution involves more than the process of natural selection. Other evolutionary processes - involving chance genetic sampling, various kinds of constraints on variation and development, and phylogenetic history - are ever present, and may even be more powerful than natural selection in the production of a given evolutionary outcome of interest. Admittedly, much of the tradition of evolutionary biology involves focusing on only those characteristics which are primarily understood through selection processes - that is, adaptations - traits that have spread through populations because of their beneficial contributions to that organism's way of living. But this does not mean that every trait - or even most traits - are evolutionary adaptations.

The problem of whether a characteristic is or is not an evolutionary adaptation is even worse in cases of behavioral traits involving learning or higher-level cognitive functions. Consider an hypothesis that I will call the 'plasticity' view: the ability to learn the details and subtleties of social interaction - call this 'social intelligence' - is an evolved capacity, one under fairly strong selection pressure in social species; moreover, there are aspects 
of social intelligence that display great flexibility of expression, depending upon social upbringing. I think that there is good supporting evidence for this view from studies of primate behavior (e.g., de Waal 1989, 1991b; de Waal and Harcourt 1992; and esp. de Waal and Johanowicz 1993). While it is clear that capacities for learning patterns of reasoning may have evolved under selection, as is suggested in the 'plasticity' approach, and are thus good candidates for being adaptations, it is always difficult to disentangle how much of a given pattern of responses is a part of the biological capacity and how much is the result of the interaction of that capacity with the organism's environment during its growth and development. Given these difficulties well-known especially since Konrad Lorenz and Nico Tinbergen's pioneering experiments on animal behavior - it is not scientifically acceptable within evolutionary biology to conclude that, because a given pattern of responses contributes to evolutionary success, then there is some 'organ' (or part of the brain) producing such a pattern, that is therefore an adaptation (see Williams 1966). This is because the 'organ' or 'module' may not actually exist as a biologically real trait, and even if it does, its current function may or may not be the same as the past function(s).

Cosmides and Tooby (1995) show much evidence of not having understood this scientific standard or its importance. For example, they describe Gould and Lewontin's discussion of the difficulties of demonstrating adaptations, as the view "that natural selection is too constrained by other factors to organize organisms very functionally" (1995: p. 71). But, of course, nowhere have Gould and Lewontin denied that organisms are very functionally organized, or denied the utility of functional reasoning in biology; rather, they have emphasized the complexity of this organization, and the evidential and methodological difficulties in empirically testing functional reasoning.

Cosmides and Tooby claim to avoid the difficult problem of using optimal design as a standard for functional and evolutionary performance: "However, when definable engineering standards of functionality are applied, adaptations can be shown to be very functionally designed - for solving adaptive problems" (1995: p. 71; emphasis added). This immediately raises the question: How do they know what is an adaptive problem?

The brain can process information because it contains complex neural circuits that are functionally organized. The only component of the evolutionary process that can build complex structures that are functionally organized is natural selection. And the only kind of problems that natural selection can build complexly organized structures for solving are adaptive problems, where "adaptive" has a very precise, narrow technical meaning (Dawkins 1986; Pinker and Bloom 1990; Tooby and Cosmides 1990a, 1992; Williams 1996) (1995: p. 76; emphasis added). 
The italicized claim will come as a surprise to most evolutionists and philosophers of biology; still, perhaps this is a harmless exaggeration. The pertinent question is whether Cosmides and Tooby have understood the theoretical and evidential standards required when investigating the evolution of structures and processes. And here we see confusion. Take the following passage, for example:

An organism's phenotypic structure can be thought of as a collection of 'design features' - micro-machines, such as the functional components of the eye or liver ... Natural selection is a feedback process that 'chooses' among alternative designs on the basis of how well they function. By selecting designs on the basis of how well they solve adaptive problems, this process engineers a tight fit between the function of a device and its structure (1995: pp. 72-83; emphasis added).

Note that there are several issues here, including a basic description of the evolution of an adaptation by natural selection, a claim about the degree to which a selection process will result in an adaptation which fulfils engineering standards ("tight fit"), and a research recommendation for approaching phenotypic traits.

Now look at the footnote to the above passage:

All traits that comprise species-typical designs can be partitioned into adaptations, which are present because they were selected for, byproducts, which are present because they are causally coupled to traits that were selected for, and noise, which was injected by the stochastic components of evolution. Like other machines, only narrowly defined aspects of organisms fit together into function systems: most of the system is incidental to the functional properties. Unfortunately, some have misrepresented the well-supported claim that selection organizes organisms very functionally as the obviously false claim that all traits of organisms are functional - something no sensible evolutionary biologist would ever maintain. Nevertheless, cognitive scientists need to recognize that while not everything in the designs of organisms is the product of selection, all complex functional organization is (Dawkins 1986; Pinker and Bloom 1990; Tooby and Cosmides 1990a, 1990b, 1992; Williams 1966, 1985) (1995: p. 73; emphasis added).

Here we see Cosmides and Tooby's ritual recitation of the objections to approaching research in the way they just recommended: "An organism's phenotypic structure can be thought of as a collection of 'design features'." I call it 'ritual recitation' because there is, in this discussion as well as in other recent writings (e.g., Pinker, Dennett), a peculiar disconnect between what the authors explicitly acknowledge as serious theoretical and evidential prob- 
lems, and how they actually theorize and evaluate evidence. Let us digress for a moment to consider this problem.

Gould and Lewontin wrote:

[The adaptationist programme] regards natural selection as so powerful and the constraints upon it so few that direct production of adaptation through its operation becomes the primary cause of nearly all organic form, function, and behaviour. Constraints upon the pervasive power of natural selection are recognized of course (phyletic inertia primarily among them, although immediate architectural constraints ... are rarely acknowledged). But they are usually dismissed as unimportant or else, and more frustratingly, simply acknowledged and then not taken to heart and invoked (1979: pp. 584-585).

That is, the problem is not that these other forces of evolution are not acknowledged, it's that they are not taken seriously.

In the discussions that ensued, Ernst Mayr made a good case for treating hypotheses of function and adaptation as reasonable and important investigative tools (1983). Mayr seems right, and his view is also compatible with Gould and Lewontin's position in the "Spandrels" paper. That is, they were not attacking the utility and importance of adaptive hypotheses in research overall; they were attacking the detailed, potentially distorting manner in which these hypotheses were pursued to the exclusion of other potential explanations. As we have seen, this argument proved too subtle for many of its targets to grasp. The issue was always a matter of the actual weight given in practice - not in lip-service - to the variety of possible causes of phenotypic traits.

Here is the standard used by Cosmides and Tooby to evaluate whether a trait is an adaptation:

To show that an aspect of the phenotype is an adaptation to perform a particular function, one must show that it is particularly well designed for performing that function, and that it cannot be better explained as a by-product of some other adaptation or physical law (1995: p. 90).

But their experiments were not designed to answer evolutionary questions at all: they did not examine whether the "aspect of the phenotype" was, in fact, a well-defined biological trait; they did not examine whether variants of the phenotype were correlated with variants of fitness; and they did not demonstrate whether that aspect of the phenotype was better explained as an adaptation or otherwise. This is why Tooby and Cosmides appear confused: while they give lip-service to a variety of possible causes of phenotypic traits, only adaptation by natural selection is given actual weight in their practice. And this is done while they claim not to be committing the errors in reasoning criticized by Lewontin and by Gould. 
But surely the most important issue for other scientists and critical readers is whether Cosmides and Tooby's claims about evolution and their social contract theory are true or not. Here I have some basic worries and questions.

\section{How can an evolutionary approach be based on 'perceived' cost and 'perceived' benefit?}

Social contract theory is directly derived from what is known about the evolutionary biology of cooperation, and is tightly constrained as a result. It explains why it should be present in the human mind, what its domain of operation will be, what kinds of implicit inferences it will generate, and what the structure of the 'look for cheaters' procedure will be (Cosmides 1989: p. 233).

Cosmides and Tooby use "constraints" to develop a computational theory of social exchange (Cosmides and Tooby 1989). They claim that any algorithm capable of solving the adaptive problem of social exchange must have certain design features. Among these features is that the algorithms produce and operate on cost/benefit representations of exchange interactions (they cite Axelrod 1984, Axelrod and Hamilton 1981, Trivers 1971). Hence, they conclude, we need, for survival, a cognitive mechanism to assess the costs and benefits of different actions. The algorithm operates on this information, in order to calculate whether the benefits outweigh the costs. Furthermore, this process should be item-independent; it should operate only on the level of the cost-benefit representations. Therefore, the algorithm should be able to handle a variety of items, so long as they are perceived as costs and benefits.

Note that the social contract suggested by Cosmides relates perceived benefits to perceived costs (1989: p. 197). She argues that providing a benefit doesn't necessarily have a cost, and the benefit doesn't have to actually be a benefit, just "something that he or she considers to be a benefit" (1989: pp. 235-236).

Cosmides can't really mean this. In order for these social interactions to play the role she assigns them in evolutionary processes, the benefit needs to be a real benefit, in terms of evolutionary fitness. In other words, the benefit must actually contribute to the probability of the reproductive success of its owner. This is perhaps clearer on the negative side. If the cost were not a real cost, i.e., a real cost to the fitness of the genotype, there would be no selection pressure against cheating. In order for Cosmides to tell a selection story about these traits involving cost and benefit, whatever is perceived socially as cost or benefit must be positively correlated with fitness. Otherwise, there is no connection at all with evolution. A selection regimen operating on perceived costs and perceived benefits is not going to produce evolutionary change unless these perceptions are systematically related to real evolutionary costs 
and benefits. It is quite striking that - in spite of the widespread discussion of these results - this has not been pointed out, nor have Cosmides and Tooby made any effort to provide the needed evidence to transform their account into a genuinely evolutionary one.

\section{Why is the standard of "explicit instruction" used when eliminating learning models?}

Social exchange is a universal, species-typical trait with a long evolutionary history. We have strong and cross-culturally reliable intuitions about how this form of cooperation should be conducted, which arise in the absence of any explicit instruction (Cosmides and Tooby 1992; Fiske 1991) (Cosmides and Tooby 1995: p. 77; emphasis added).

This absence of explicit instruction is then used as evidence that this pattern of behaviors or preferences is not learned, and hence is not a product of a more general social-learning ability, such as the 'plasticity' view discussed in the previous section. But surely the presence of 'explicit instruction' is not a legitimate prerequisite for a task being learned; the development of highly complex social skills in non-human primates is not associated with much explicit instruction at all (see de Waal 1989, 1991a; de Waal and Johanowicz 1993; Wrangham et al. 1994). Cosmides and Tooby claim that learning is not needed, but they have not supplied or evaluated evidence for and against this claim. As Gigerenzer and Hug clearly recognize, all of these experiments are insufficient for eliminating other, non-evolutionary explanations, such as Pragmatic Reasoning Schemas, or some other general social-learning theory. Cosmides and Tooby seem over-eager to eliminate rival psychological hypotheses that are based on more multi-purpose "modules" than the "highly functionally specialized" ones that they theorize (1995: p. 70). While they claim that evolutionary biology favors their more specialized modules, there is nothing either in their discussion or in evolutionary theory that supports this assertion.

\section{Why the pressure on efficiency? Why not just look at all the cards?}

In the Wason selection task, the subject is asked to turn over all and only the cards necessary to find out if the conditional is false; turning over all the cards is implicitly discouraged by the directions of the experiment. When we consider the test as reflecting an important type of evolutionary scenario, though, why assume that such efficiency of thought was selectively desirable? Why not just turn over all the cards? Why not get as much information as you can, and then decide? Of course, it is not impossible that speed of deliberation might have been a factor in our evolutionary past, but the burden of proof is 
on those who claim that it was; there is no justification offered for it being assumed. It seems to me likely that the efficiency requirement is simply a remnant from the original context of the Wason selection task - as a test of logical competence, within a non-evolutionary approach in psychology.

\section{Why assume that social intelligence about social exchange evolved during the Pleistocene?}

The evolutionary psychology research program, as outlined by Cosmides, Tooby, Barkow, and Symons, rests on taking the Pleistocene environment as the crucial evolutionary environment. The thought is that the hominid lineage evolved during this period into the basic modern human being; thus, features of our minds that are distinctly human must have evolved during this transition from pre-human to human. But is it reasonable to think that practices of social exchange are distinctly human? Evidence of extremely sophisticated social intelligence has come from our closest relatives, the chimpanzees and bonobos, some of which seems to suggest paradigmatic social exchange behavior (de Waal 1991a, b; de Waal and Harcout 1992; de Waal and Luttrell 1988; Wrangham et al. 1994). Wouldn't the chimps and bonobos also need to have specialized modules, for the same reasons that human beings did? One reviewer of The Adapted Mind proposes that the social exchange modules evolved in the common ancestors of chimps and human beings, about six million years ago, thus making "the environmental conditions and lifestyles of hunter-gatherers in the Pleistocene ... [of] ... limited evolutionary significance" (Mithen 1997: p. 102).

\section{Conclusions}

I applaud the fact that academic psychology is finally being reunited with evolutionary biology; the authors criticized in this paper deserve credit for bringing overdue consideration of evolutionary issues to the fore. Much credit also goes to Cosmides for her pursuit of a particular focus on cost-benefit reasoning; the recent evidence confirms at least some other initial ideas, i.e., that some human beings are especially good at such reasoning, and that it facilitates performance on certain logical tasks. Perhaps the most disturbing aspect of this research program is that its originators and defenders overreach. If the evidence is so good, why weaken your position by mischaracterizing it as a crucial experiment to eliminate rival theories? If you're not presenting any empirical evidence that would support a claim of evolutionary adaptation, why say that you are? Why make particular evolutionary claims at all, when they are not tested? 
I draw several morals from the story.

First, the lack of basic consensus in psychology has made the field ripe for the sort of exaggerated claims made by these evolutionary psychologists. Second, a lack of awareness of the real standards of evidence in evolutionary biology can lead to acceptance of unwarranted or highly controversial claims, among psychologists seeking a definitive way of choosing among the competing hypotheses offered for the content effects of the Wason selection task. Philosophers of mind suffer the same risk.

Again, it is essential to reject the false dichotomy that is frequently set up rhetorically in these discussions: the choice is not between accepting the particular evolutionary psychological proposal under consideration, or rejecting an evolutionary approach to psychological or social traits altogether. These researchers have taken a step in the right direction; this doesn't mean we must follow them all the way down the path.

Finally, this case provides an opportunity to reflect on just how important it is that scientists in other fields be vigilant about the points insisted on by Lewontin and other evolutionary biologists. Virtually all of the writers in evolutionary psychology dutifully cite Lewontin's work, and state that, of course, they are not doing what he warned against. Our apparent human affinity for design explanations and stories about our species has many dangers, chief among them that we don't evaluate adaptive evolutionary explanations as carefully as we should. This was Lewontin's warning in the nineteen-seventies against the excesses of sociobiology; evolutionary psychology is in peril of suffering the same scientific ignominy unless its promoters clean up their act.

\footnotetext{
Notes

* I would like to thank Carl Anderson, Mark Borrello, Greg Ray, David Smith, and Rasmus Winther for research assitance during various segments of my investigation of this work. Marc Feldman, Greg Ray, and Dan Sperber contributed substantively to this discussion. As this critical project was in progress for nine years, there are many other people to be thanked, including audiences at the CNRS in Paris, Brussels, and UC Davis, as well as my seminar participants at Harvard in Spring of 1998. Finally, so much is due to Dick Lewontin that I refuse to embarrass him by detailing the debt.

1 Lewontin 1978, 1985.

2 Gould and Lewontin 1979.

3 Cosmides and Tooby 1995: p. 71; Pinker and Bloom 1992: p. 454.

4 The birth of "evolutionary psychology" was celebrated in Tooby (1985), and other early developments in the field include Cosmides and Tooby (1989), Symons (1987), Shepard (1987), and Tooby and DeVore (1987). More recently, we find The Adapted Mind, coedited by Barkow, Cosmides, and Tooby, and Steven Pinker's How The Mind Works.

5 'Deduction or Darwinian algorithms?: An explanation of the 'elusive' content effect on
} 
the Wason selection task," Doctoral dissertation, Harvard University. This research was first published in "The logic of social exchange: Has natural selection shaped how humans reason? Studies with the Wason selection task" (1989).

6 (“Awards: 1989," Science 243: 672, 3 Feb 1989).

7 Economist 326 (1993): 82.

8 Blonder, Lee (1993) American Anthropologist 95: 778.

9 Miller, G. F. and Todd, P. M. (1994) Adaptive Behavior 3(1): 83-95.

10 Note that on this description, domain-specific mechanisms are considered additions to and not replacements for - domain-general ones.

11 Cheng and Holyoak (1983, 1984, 1995); Cheng, Holyoak, Nisbett and Oliver (1986); Nisbett, Fong, Lehman and Chang (1987).

12 Note that Cosmides assumes that genetic and environmental specificity are opposed. This assumption has been criticized extensively by Lewontin $(1974,1985,1990)$.

\section{References}

Axelrod, R.: 1984, The Evolution of Cooperation, Basic Books, New York.

Axelrod, R. and Hamilton, W. D.: 27 March 1981, 'The Evolution of Cooperation', Science 211, 1390-1396.

Barkow, J., Cosmides, L. and Tooby, J.: 1992, The Adapted Mind, Oxford University Press, New York.

Blonder, L.: September 1993, 'Review of the Adapted Mind', American Anthropologist 95, 777-778.

Cheng, P. W. and Holyoak, K. J.: 1983, Schema-based inferences in deductive reasoning. Anaheim, 25th Annual Meeting of the American Psychological Association.

Cheng, P. W. and Holyoak, K. J.: 1984, Pragmatic schemas for deductive reasoning. San Antonio, 25th Annual Meeting of the Psychonomic Society.

Cheng, P. W. and Holyoak, K. J.: 1985, 'Pragmatic Reasoning Schemas', Cognitive Psycho$\log y$ 17, 391-416.

Cheng, P. W. and Holyoak, K. J.: 1989, 'On the Natural Selection of Reasoning Theories', Cognition 33, 285-313.

Cheng, P. W. and Holyoak, K. et al.: 1986, 'Pragmatic Versus Syntactic Approaches to Training Deductive Reasoning', Cognitive Psychology 18, 293-328.

Chomsky, N.: 1975, Reflections on Language, Random House, New York.

Chomsky, N.: 1980, Rules and Representations, Columbia University Press, New York.

Cosmides, L.: 1985, 'Deduction or Darwinian Algorithms?: An Explanation of the 'Elusive' Content Effect on the Wason Selection Task', Ph.D. Dissertation, Harvard University.

Cosmides, L.: 1989, 'The Logic of Social Exchange: Has Natural Selection Shaped How Humans Reason? Studies with the Wason Selection Task', Cognition 31, 187-276.

Cosmides, L. and Tooby, J.: 1987, 'From Evolution to Behavior: Evolutionary Psychology as the Missing Link', in J. Dupre (ed.), The Latest on the Best: Essays on Evolution and Optimality, MIT Press, Cambridge, MA, pp. 277-306.

Cosmides, L. and Tooby, J.: 1995, 'Beyond Intuition and Instinct Blindness: Toward an Evolutionary Rigorous Cognitive Science', in J. Mehler and S. Franck (eds.), Cognition on Cognition, MIT Press, Cambridge, MA, pp. 69-105.

Dawkins, R.: 1986, The Blind Watchmaker, Norton, New York.

Economist (no author noted): 1993, Review of The Adapted Mind 326, 82. 
Fiske, A. P.: 1991, Structures of Social Life: The Four Elementary Forms of Human Relations, Free Press, New York.

Fodor, J. A.: 1983, The Modularity of Mind: An Essay on Faculty Psychology, MIT Press, Cambridge, MA.

Gigerenzer, G. and Hug, K.: 1992, 'Domain-specific Reasoning: Social Contracts, Cheating, and Perspective Change', Cognition 43, 127-171.

Gould, S. J. and Lewontin, R. C.: 1979, 'The Spandrels of San Marco and the Panglossian Paradigm: A Critique of the Adaptationist Programme', Proceedings of the Royal Society of London B205, 581-598.

Levins, R. and Lewontin, R. C.: 1985, The Dialectical Biologist, Harvard University Press, Cambridge, MA.

Lewontin, R. C.: 1974, The Genetic Basis of Evolutionary Change, Columbia University Press, New York.

Lewontin, R. C.: 1978, 'Adaptation', Scientific American 239(3), 212-230.

Lewontin, R. C.: 1985, 'Adaptation', in R. Levins and R. C. Lewontin (eds.), The Dialectical Biologist, Harvard University Press, Cambridge, MA, pp. 65-84, originally published as 'Adattamento' in Enciclopedia Einaudi, vol. 1. Turin, 1977.

Lewontin, R. C.: 1991, Biology as Ideology: The Doctrine of DNA, Harper Collins, New York.

Mayr, E.: 1983, 'How to Carry Out the Adaptationist Program?' American Naturalist 121, 324-334.

Miller, G. F. and Todd, P. M.: 1994, 'A Bottom-up Approach with a Clear View of the Top: How Evolutionary Psychology Can Inform Adaptive Behavior Research', Adaptive Behavior 3(1), 83-95.

Mithin, S.: Spring 1997, 'Review of the Adapted Mind', Journal of Anthropological Research 53, 100-102.

Nisbett, R. E. and Cheng, P. W.: 1988, Conditional reasoning, 29th Annual Meeting of the Psychonomic Society, Chicago.

Nisbett, R. E., Fong, G. T., Lehman, D. and Cheng, P. W.: 1987, ‘Teaching Reasoning', Science 238, 625-631.

Pinker, S.: 1997, How the Mind Works, W.W. Norton, New York.

Pinker, S. and Bloom, P.: 1990, 'Natural Language and Natural Selection', Behavioral and Brain Sciences 13, 707-784. Reprinted (1992) in J. Barkow, L. Cosmides and J. Tooby (eds.), The Adapted Mind, pp. 451-493.

Shepard, R. N.: 1987, 'Evolution of a Mesh between Principles of the Mind and Regularities of the World', in J. Dupre (ed.), The Latest on the Best: Essays on Evolution and Optimality, Blackwell, Oxford.

Symons, D.: 1987, 'If We're All Darwinians, What's the Fuss About?', in C. Crawford, D. Krebs and M. Smith (eds.), Sociobiology and Psychology, Erlbaum, Hillsdale, NJ.

Tooby, J.: 1985, 'The Emergence of Evolutionary Psychology', in D. Pines (ed.), Emerging Syntheses in Science, Santa Fe Institue, Santa Fe, NM, pp. 67-75.

Tooby, J. and DeVore I.: 1987, 'The Reconstruction of Homind Behavioral Evolution through Strategic Modeling', in W. G. Kinzey (ed.), The Evolution of Human Behavior: Primate Models, State University of NY Press, New York, NY, pp. 183-237.

Tooby, J. and Cosmides, L.: 1989, 'Evolutionary Psychology and the Generation of Culture, Part I: Theoretical Considerations', Ethology and Sociobiology 10, 29-49. 'Pt II: Case study: A Computational Theory of Social Exchange', Ethology and Sociobiology 10, 5197.

Tooby, J. and Cosmides, L.: 1990a, 'The Past Explains the Present: Emotional Adaptations and the Structure of Ancestral Environments', Ethology and Sociobiology 11, 375-424. 
Tooby, J. and Cosmides, L.: 1990b, 'On the Universality of Human Nature and the Uniqueness of the Individual: The Role of Genetics and Adaptation', Journal of Personality 58, 17-67.

Tooby, J. and Cosmdies, L.: 1992, 'The Psychological Foundations of Culture', in J. Barkow, L. Cosmides and J. Tooby (eds.), The Adapted Mind: Evolutionary Psychology and the Generation of Culture, Oxford University Press, New York, pp. 19-136.

Trivers, R.: 1971, 'The Evolution of Reciprocal Altruism', Quarterly Review of Biology 46, 35-57.

de Waal, F. B. M.: 1989, Peacemaking among Primates, Harvard University Press, Cambridge, MA.

de Waal, F. B. M.: 1991a, 'The Chimpanzee's Sense of Social Regularity and its Relation to the Human Sense of Justice', American Behavioral Scientist 34(3), 335-349.

de Waal, F. B. M.: 1991b, 'Complementary Methods and Convergent Evidence in the Study of Primate Social Cognition', Behaviour 118, 297-320.

de Waal, F. B. M. and Harcourt, A. H. (eds): 1992, Coalitions and Alliances in Humans and Other Animals, Oxford University Press, New York.

de Waal, F. B. M. and Johanowicz, D. L.: 1993, 'Modification of Reconciliation Behavior through Social Experience: An Experiment with Two Macaque Species', Child Development 64, 897-908.

de Waal, F. B. M. and Luttrell, L. M.: 1988, 'Mechanisms of Social Reciprocity in Three Primate Species: Symmetrical Relationship Characteristics or Cognition?' Ethology and Sociobiology 9, 101-118.

Williams, G. C.: 1966, Adapation and Natural Selecton, Princeton University Press, Princeton.

Williams, G. C.: 1985, 'A Defense of Reductionism in Evolutionary Biology', Oxford Surveys in Evolutionary Biology 2, 1-27.

Wimmer, H. and Perner, J.: 1983, 'Beliefs about Beliefs: Representation and Constraining Function of Wrong Beliefs in Young Children's Understanding of Deception', Cognition 13, 103-128.

Wrangham, R. W., McGrew, W. C. and de Waal, F. B. M. (eds): 1994, Chimpanzee Cultures, Harvard University Press, Cambridge, MA. 
